\title{
CORRECTION
}

\section{Correction to: AUGS/IUGA scientific meeting}

\section{Abstracts of poster presentations, IUGA 44th annual meeting - Nashville, TN, USA, September}

24-28, 2019

\section{Zhenwei Xie $^{1}$}

Published online: 10 September 2020

(C) The International Urogynecological Association 2020

\section{Correction to: International Urogynecology Journal (2019) 30 (Suppl 1):S219-S380 \\ https://doi.org/10.1007/s00192-019-04116-3}

In the originally published version of the Abstracts article, the figure presented in Poster 204 entitled "Exosomes derived from fibroblasts in anterior vaginal wall associated with the pathogenesis of female stress urinary incontinence by promoting fibroblasts migration" found on pages S306-S307 was not correct. The correct figure is shown below.

a

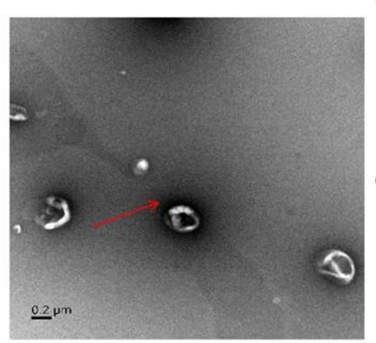

d

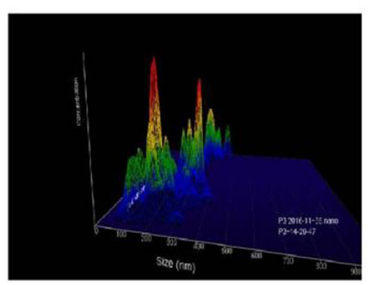

b

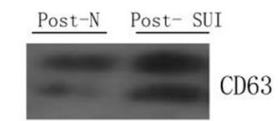

c
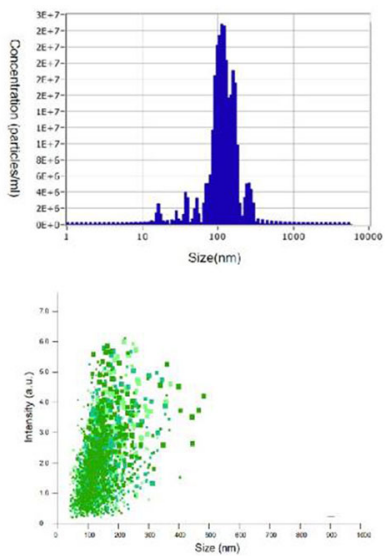

Publisher's note Springer Nature remains neutral with regard to jurisdictional claims in published maps and institutional affiliations.

The online version of the original article can be found at https://oi.org/ 10.1007/s00192-019-04116-3

Zhenwei Xie

xiezw@zju.edu.cn

1 Department of Gynecology, Women's Hospital School of Medicine, Zhejiang University, Hangzhou, Zhejiang, China 